\title{
Seasonal dynamics of cyanobacteria and eukaryotic phytoplankton in a multiple- reservoir recycling irrigation system
}

\author{
Ping Kong ${ }^{*}$ (D), Patricia Richardson and Chuanxue Hong
}

\begin{abstract}
Background: Agricultural runoff recycling systems are manmade aquatic ecosystems of growing significance to global water sustainability, crop health, and production. This study investigated the seasonal dynamics of microbial community in a three-reservoir recycling irrigation system with a stepwise water flow and compared with that of an adjacent runoff-free stream. Runoff water from all production areas was captured in a sedimentation reservoir which overflowed to a transition reservoir then retention reservoir through a culvert. Stream water was pumped to replenish the reservoirs as needed during growing seasons.
\end{abstract}

Results: 165 rDNA PCR clone libraries of quarterly water samples from three reservoirs and one stream were sequenced, and 575 operational taxonomic units (OTUs) were identified and assigned to cyanobacteria, eukaryotic phytoplankton, and other bacteria. When compared to the stream, three reservoirs consistently had low microbial diversity. A distinct seasonal pattern of microbial community structure was observed for each reservoir and the stream. Stream was consistently dominated by other bacteria. Retention reservoir was dominated by cyanobacteria during the summer and fall and eukaryotic phytoplankton during the winter and spring. Sedimentation reservoir was dominated by cyanobacteria beginning in the spring but that dominance was altered when water was pumped from the stream from early spring to fall seasons. Transition reservoir had the greatest shift of microbial community structure, being dominated by other bacteria in the summer, cyanobacteria in the fall, and eukaryotic phytoplankton in the winter and spring. Water temperature and ammonium level were the two most important contributing factors to the seasonality of microbial community in these reservoirs.

Conclusions: The three recycling irrigation reservoirs consistently had lower microbial diversity and distinct community structure when compared to the stream. These reservoirs were typically dominated by cyanobacteria during warm seasons and eukaryotic phytoplankton during cool seasons. This seasonal pattern was altered when water was pumped from the stream. The cyanobacteria dominance was associated with rising water temperature and ammonium level. These results highlight the importance of preventing agricultural runoff from entering natural waterways and water resources and provide a useful framework for further investigations into the ecological processes of this emerging ecosystem.

Keywords: Bacteria, Cyanobacteria, Phytoplankton, Seasonal dynamics, Water recycling, Water quality

\footnotetext{
*Correspondence: pkong@vt.edu

Hampton Roads Agricultural Research and Extension Center, Virginia Tech,

1444 Diamond Springs Road, Virginia Beach, VA 23455, USA
} 


\section{Introduction}

Agricultural runoff recycling systems are aquatic ecosystems of growing significance to global water and environmental sustainability, crop health, and production. Water scarcity and drought are among the most pressing sustainability issues in the twenty-first century (Brown and Ayres 1998). Agriculture uses $70 \%$ of the overall global consumptive water (Holdren 2008) and generates huge quantities of runoff, which is the leading source of impairments to rivers, lakes, and wetlands in the USA (http://water.epa.gov/polwaste/nps/agriculture_facts.cfm) and elsewhere (Diaz and Rosenberg 2008; Ferber 2001; Guo 2007). The amount of irrigation runoff can be substantial with overhead irrigation systems which have water delivery efficiency as low as $20 \%$ (Haman et al. 2005). While capture and reuse of runoff for irrigation can tremendously increase agricultural water efficiency and reduce nonpoint source pollution (Hong et al. 2009), it also raises concerns about algal bloom, water quality deterioration, and plant health risk associated with pathogen recycling and redistribution (Hong and Moorman 2005; Hong et al. 2014; Kong and Hong 2014; Kong et al. 2009; Kong et al. 2012a, b).

Recent studies found that recycling irrigation system design can influence microbial diversity and population and water quality in associated reservoirs (Ghimire et al. 2011; Hong et al. 2014; Kong et al. 2017; Zhang et al. 2015a, b; Zhang et al. 2016). According to a study in the spring, cyanobacteria were predominant in sedimentation reservoirs but not in other downstream reservoirs of multiple-reservoir recycling irrigation systems (Kong et al. 2017). Another study on single-reservoir recycling irrigation system showed that populations of Phytophthora species, a group of important algae-like plant pathogens, decreased with increasing distance from runoff entrance (Ghimire et al. 2011). These studies suggest that multiple-reservoir system design may be effective for preventing pathogen dissemination by extending runoff turnover time and for control of algal bloom by sedimentation. However, it is not clear whether microbial community structure changes with time in these recycling irrigation reservoirs, especially during the summer and fall when water consumption and recycling dramatically increases.

Seasonal variations of phytoplankton in natural lakes and reservoirs have been well documented (Katsiapi et al. 2013; Marshall 2013; Rozon and Short 2013; Singh et al. 2014). Cyanobacterial blooms occur commonly in the summer and fall, while chlorophyte blooms occur at the beginning of winter in these aquatic environments (Katsiapi et al. 2013; Marshall 2013). In a single-reservoir recycling irrigation system in Virginia, USA, chlorophyll $a$ level fluctuated over time (Hong et al. 2009). The objective of this study, focusing on phytoplankton, was to further investigate the seasonality of microbial diversity and community structures in a multi-reservoir recycling irrigation system with a stepwise water flow and compare to those in an adjacent stream.

\section{Materials and methods}

Reservoirs, water sampling, and metadata

Three reservoirs (VA11, VA12, and VA13) at an ornamental crop nursery and one adjacent stream (VA10) in eastern Virginia were included in this study. VA10 was on the property edge and did not receive runoff from any of the nursery production areas. VA11 was a small sedimentation reservoir, capturing runoff water from all production areas on the property. It also received water from VA10 from early spring to fall months to replenish the three reservoirs in the recycling irrigation system. When VA11 was full, water overflowed to VA12, a 0.8hectare transition and irrigation reservoir, hereafter referred to as a transition reservoir. VA13, a 6.1-hectare spring-fed natural lake, is a retention and irrigation reservoir which was replenished with water from VA12 through a culvert. The general water flow among the three reservoirs and stream is illustrated in Fig. 1. The summer and fall of 2012 were pretty dry, the stream completely dried up in June. As a result, water was also pumped from VA13 to replenish VA12. There also was a significant storm event in August of 2012 during which stream water level surged and directly flowed to both VA11 and VA12.

Three 1-1 water samples were collected from the center of each reservoir and the stream quarterly from spring of 2012 to early 2013. They were taken at approximately $20 \mathrm{~cm}$ below the surface near a 6600V2-4 Multiparameter DataSonde deployed in each reservoir and the stream (Fig. 1). The collected water samples were kept in a cooler and transported to the laboratory for processing. To determine the nutrient level, 10-ml aliquots of each sample were immediately filtered through a $0.22-\mu \mathrm{m}$ membrane, frozen at $-20{ }^{\circ} \mathrm{C}$, and shipped to Brookside Labs (New Bremen, OH, USA) for analysis. To extract DNA, the remaining water samples were centrifuged at $12,230 \times \mathrm{g}$ for $50 \mathrm{~min}$ in an Avanti J26XP (Beckman Coulter, Atlanta, GA, USA). The sampling dates, water quality data, and nutrient levels of each sample are listed in Table 1.

\section{DNA extraction, PCR clone library construction, and sequencing}

Immediately after water samples were centrifuged, supernatants of individual samples were filtered through $0.22-\mu \mathrm{m}$ membranes and pellets were collected. DNA was extracted from the filters and pellets, then quantified as described previously (Kong et al. 2017). Twenty nanograms of DNA from both filter and pellet of each sample was combined and used as template in PCR. To amplify 


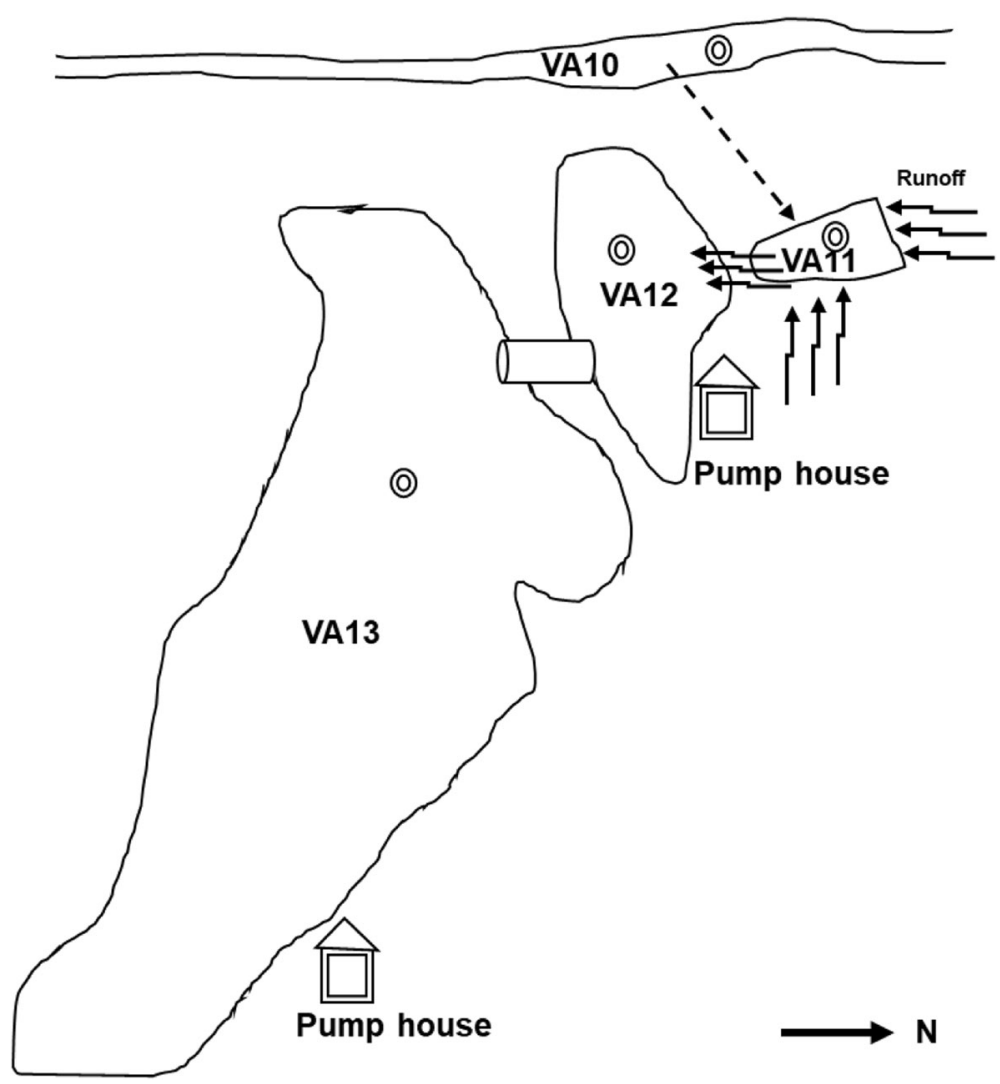

Fig. 1 Schematic illustration of general water flow among three reservoirs and one stream in a recycling irrigation system investigated in this study. VA10, a stream, did not receive runoff water from any production areas and supplied water to VA11 during early spring and summer months. VA11, a sedimentation reservoir, received runoff from all production areas of the nursery, and when it was full, water overflowed into VA12, a transition and irrigation reservoir. VA13, an irrigation reservoir, was replenished with water from VA12 through a culvert. The double circle indicates the point of sampling in each reservoir and stream

the 16S rDNA genes in cyanobacteria and in chloroplasts of eukaryotic phytoplankton, the primers CYA359F and CYA781R (Nübel et al. 1997) were used. PCR and construction of clone libraries of sample PCR amplicons were conducted as previously described (Kong et al. 2017). More than 100 clones were randomly selected from the library of each sample and amplified with vector T3 and T7 primers for sequencing.

\section{Sequence process and analysis}

Poor-quality sequences of samples were removed based on the quality control report from the sequencing facility. Remaining sequences were edited using Mega 6 (Tamura et al. 2013) and Mothur software package V.1.33.3 as previously described (Kong et al. 2017). Clustering, classification, and phylogenetic analysis of the edited sequences was performed using Mothur. Operational taxonomic units (OTUs) were used for building clusters which were determined by a distance matrix of the sequences from all water samples at a pairwise distance cutoff of 0.15 (a percent similarity threshold of $85 \%)$. OTUs were then classified based on known sequences in a constructed cyanobacteria reference library or through Arb-Silva-SINA against Silva and Greengenes $16 \mathrm{~S}$ gene libraries at the default setting of $70 \%$ sequence identity. OTUs were clustered through a neighbor-joining tree at distance cutoffs of 0.03 for phylogeny analysis. "Unclassified" OTUs were grouped based on their closest positions to knowns in the phylogenetic tree (Additional file 2: Figure S1). A taxon was assigned with a name of knowns in the closest cluster or assigned as unknown if there were no knowns nearby.

\section{Microbial diversity analysis}

Alpha diversity as an indicator of complexity of the samples was measured by inverse Simpson index. Beta diversity or the membership and microbial community composition as well as their relation to environmental variables were measured using OTU- and taxon-based approaches. Both alpha and beta diversity were determined through Mothur (Schloss et al. 2011). In OTU-based analysis, a heat map was generated through $\mathrm{R}$ version 3.1.0 (http://www.R-project.org/) (R Core Team 2013) with a shared file of OTUs from individual reservoirs at cutoffs 
Table 1 Water quality and nutrient levels in a multiple-reservoir water recycling system at the time of sampling

\begin{tabular}{|c|c|c|c|c|c|c|c|c|c|c|c|}
\hline \multirow[t]{2}{*}{ Season (date) } & \multirow[t]{2}{*}{ Reservoir ${ }^{y}$} & \multicolumn{6}{|c|}{ Water quality ${ }^{z}$} & \multicolumn{4}{|c|}{ Nutrient level } \\
\hline & & $\begin{array}{l}\text { Chla } \\
(\mu \mathrm{g} / \\
\mathrm{L})\end{array}$ & $\begin{array}{l}\text { DO } \\
\text { (mg/ } \\
\text { L) }\end{array}$ & $\begin{array}{l}E C \\
(\mu S / \\
c m)\end{array}$ & $\mathrm{pH}$ & $\begin{array}{l}\text { Temp } \\
\left({ }^{\circ} \mathrm{C}\right)\end{array}$ & $\begin{array}{l}\text { Turb } \\
\text { (NTU) }\end{array}$ & $\begin{array}{l}\mathrm{NH}_{4} \\
(\mathrm{mg} / \mathrm{L})\end{array}$ & $\mathrm{NO}_{3}$ & $\mathrm{NO}_{2}$ & $\mathrm{PO}_{4}$ \\
\hline \multirow[t]{4}{*}{ Spring $^{\times}(4 / 11 / 12)$} & VA10 & 0.55 & 8.58 & 243.00 & 5.40 & 12.28 & 3.90 & 0.29 & 7.42 & 0.09 & $<0.01$ \\
\hline & VA11 & 24.30 & 9.07 & 437.33 & 6.32 & 16.42 & 52.10 & 5.18 & 12.07 & 0.09 & 1.76 \\
\hline & VA12 & 32.90 & 9.49 & 252.00 & 6.65 & 18.08 & 7.7 & 2.54 & 5.17 & 0.09 & 0.69 \\
\hline & VA13 & 2.5 & 9.85 & 192.93 & 7.46 & 17.60 & 45.3 & 0.29 & 0.46 & 0.09 & 0.01 \\
\hline \multirow[t]{4}{*}{ Summer $(7 / 16 / 12)$} & VA10 & 0.70 & 6.79 & 241.67 & 5.87 & 20.75 & 3.60 & 0.29 & 25.78 & 0.11 & 0.09 \\
\hline & VA11 & 23.60 & 6.20 & 741.33 & 6.12 & 28.95 & 17.00 & 0.65 & 165.52 & 0.81 & 18.92 \\
\hline & VA12 & 31.40 & 10.40 & 328.33 & 7.75 & 29.85 & 2.17 & 0.48 & 50.31 & 1.79 & 6.56 \\
\hline & VA13 & 3.71 & 10.39 & 311.00 & 10.3 & 29.66 & 17.02 & 0.29 & 0.15 & 0.09 & 0.09 \\
\hline \multirow[t]{4}{*}{ Fall (10/1/12) } & VA10 & 0 & 8.11 & 244.00 & 6.02 & 17.32 & 2.60 & 0.29 & 39.42 & 0.09 & 0.09 \\
\hline & VA11 & 26.73 & 5.83 & 343.67 & 6.65 & 19.92 & 6.20 & 1.16 & 86.82 & 1.72 & 15.64 \\
\hline & VA12 & 51.07 & 7.38 & 230.00 & 7.22 & 22.35 & 14.57 & 0.29 & 41.8 & 0.66 & 8.14 \\
\hline & VA13 & 24.87 & 7.06 & 181.33 & 9.42 & 21.63 & 76.07 & 0.29 & 0.09 & 0.09 & 0.09 \\
\hline \multirow[t]{4}{*}{ Winter (1/22/13) } & VA10 & 1.33 & 9.75 & 236.00 & 5.57 & 8.39 & 1.27 & 0.09 & 21.94 & 0.16 & 0.09 \\
\hline & VA11 & 11.60 & 11.88 & 71.00 & 6.23 & 6.59 & 37.17 & 0.45 & 6.81 & 0.19 & 2.25 \\
\hline & VA12 & 13.60 & 11.4 & 79.67 & 6.79 & 7.47 & 33.30 & 0.21 & 4.01 & 0.28 & 2.52 \\
\hline & VA13 & 45.03 & 8.93 & 240.00 & 5.79 & 12.86 & 6.13 & 0.09 & 2.42 & 0.09 & 0.09 \\
\hline
\end{tabular}

${ }^{x}$ Data has been published (Kong et al. 2017)

${ }^{\mathrm{y}}$ Runoff from production areas was channeled into VA11 which overflowed into VA12 then to VA13. VA10 was an independent small stream

${ }^{z}$ Water quality reading at the time of sampling: Chla chlorophyll $a, D O$ dissolved oxygen, EC electrical conductivity, Temp temperature, Turb turbidity

of 0.03. The map included the relative abundance of dominant OTUs in each reservoir which contained ten or more clones and a dendrogram showing relationships between the reservoirs. Variations of taxon composition in the reservoirs were investigated using non-metric multidimensional scaling (NMDS) by the vegan "metaMDS" function in R (Oksanen et al. 2015). To analyze the correlation between community composition and environmental variables that included water quality and nutrient Metadata (Table 1), the vegan "envfit" function was used to fit the variables into the NMDS ordination.

\section{Results}

A total of 1600 clones were generated from the water samples of the three-reservoir recycling irrigation system and the associated stream. Among them, 1421 highquality partial $16 \mathrm{~S}$ sequences were selected and classified into 575 OTUs (Additional file 1: Table S1). Representative sequences of the identified OTUs were deposited into the NCBI GenBank (504 in Accession \#KT 270949271452 and 71 within KP 769594-769768).

\section{Seasonal patterns of microbial diversity}

There were distinct seasonal patterns in the number of OTUs detected among the three reservoirs and the stream (Fig. 2a). Consistently high number of OTUs was detected in the stream, VA10, across all four sampling times. The OTU number detected from VA11 was also high during the spring, but it dropped during the summer and fall, and then increased slightly during the winter. Comparatively, the number of OTUs in the transition and retention reservoirs (VA12 and VA13) was lower and varied considerably, peaking in the summer and bottoming in the fall.

The inverse Simpson index was consistently low in all three reservoirs (VA11, VA12, and VA13) when compared to that of the stream, VA10 (Fig. 2b). The index climbed after the spring, peaked in the fall, then slightly declined in the winter. On the other hand, VA11 had index values and dynamics similar to VA12 and VA13 although it appeared slightly more complex in the fall and winter seasons (Fig. 2b).

Cyanobacteria, eukaryotic phytoplankton, and other bacteria detected are summarized in Table 2 . The bacteria group had the greatest diversity with 414 OTUs. This was particularly obvious with 158 OTUs detected in the summer and 113 OTUs in the fall. Comparatively, the other two groups were not as diverse with 121 OTUs for cyanobacteria and 127 for eukaryotic phytoplankton.

The greatest cyanobacterial diversity was detected during the summer (51 OTUs) and the least during the winter (19 OTUs) with the spring and fall in between. Specifically, some cyanobacterial OTUs such as those of Aphanizomenon, Limnothrix, Microcystis, and Synechococcus 


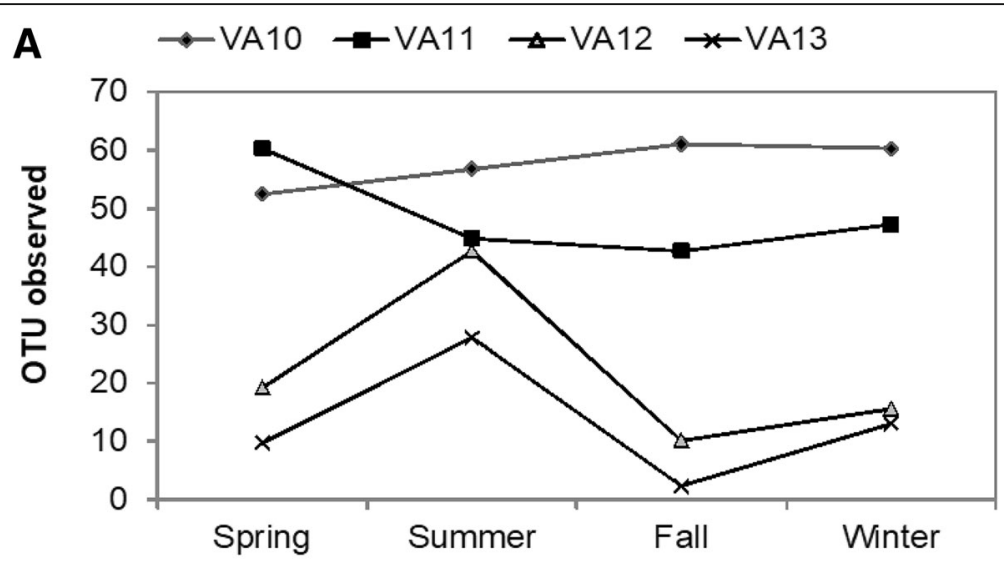

B

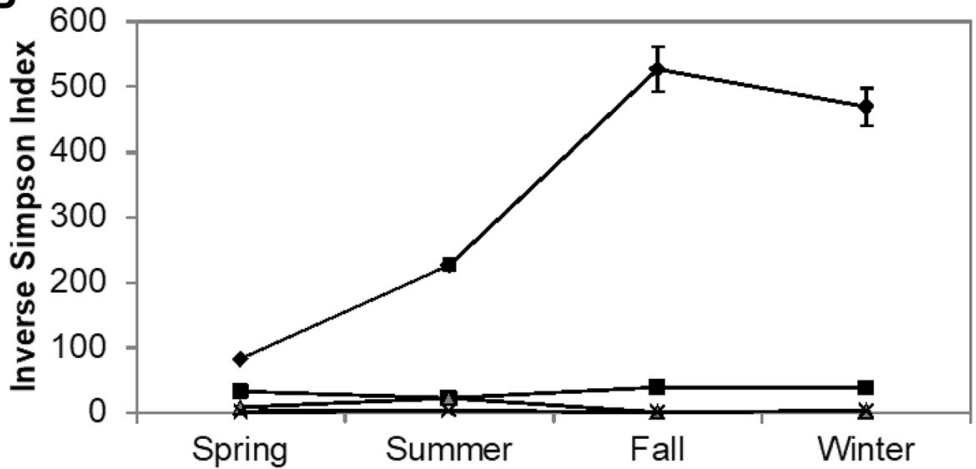

Fig. 2 Seasonal alpha diversity of microbes in three reservoirs and one stream. a Number of operational taxonomic units (OTUs). $\mathbf{b}$ Inverse Simpson index. Bars in the lines are standard errors of 65 clone sequences in individual samples

were predominant or only present in the summer. There were four classified subgroups of eukaryotic phytoplankton. As shown by most dominant subgroups: Chlorophyta (33 OTUs) and Stramenopila (49 OTUs), they were more diverse in cool than warm seasons (106 vs. 21 OTUs). This seasonal pattern was opposite to that of the bacteria group. Overall, more diverse cyanobacteria and other bacteria were detected during the summer while more phytoplankton during the cool seasons (winter and spring).

\section{Seasonal patterns of microbial community structure}

There were four distinct seasonal patterns of microbial community structure as measured by the relative percentage of OTUs (Fig. 3) and representative clone among three groups (Fig. 3b). First, other bacteria consistently dominated in the stream, VA10, irrespective of the season. This is likely attributed to the nonpolluted nature of stream water. Second, other bacteria also dominated in VA11 during the summer then gradually declined through the fall and winter. These bacteria were carried over from VA10, when stream water was pumped to replenish VA11. Eukaryotic phytoplankton became dominant in the winter while cyanobacteria codominant in the spring. Third, VA12, the transition reservoir, had the greatest shift of microbial community structure, being dominated by other bacteria in the summer, cyanobacteria in the fall, and eukaryotic phytoplankton in the winter and spring, respectively. Fourth, VA13, the retention reservoir, was dominated by cyanobacteria during the warm seasons (summer and fall) and eukaryotic phytoplankton during the cool season (winter and spring). As shown in the heatmap (Fig. 3c), there were clear associations in the dominant group and subgroups between connected reservoirs and consecutive seasons. For example, OTU1 or Microcystis sp. dominated in two connected reservoirs (VA12 and VA13) during two consecutive seasons (summer and fall).

Overall, cyanobacteria as represented by Microcystis spp. typically dominated these nutrient-rich reservoirs during warm seasons while eukaryotic phytoplankton dominated during cool seasons as shown in VA13 (Fig. $3 \mathrm{a}, \mathrm{b})$. However, cyanobacteria as the dominant group in VA11 during warm seasons were replaced by other bacteria from the stream. During the hot summer, substantial quantity of stream water was pumped to replenish VA11 then VA12 and VA13. As a result, other bacteria were carried over from the stream and dominated VA11 almost exclusively and to a lesser extent in the 
Table 2 Diversity and populations of cyanobacteria and phytoplankton identified from a multiple-reservoir water recycling system over four seasons

\begin{tabular}{|c|c|c|c|c|c|c|c|}
\hline \multirow[t]{2}{*}{ Group } & \multirow[t]{2}{*}{ Taxon $^{x}$} & \multicolumn{4}{|c|}{ No. of OTUs } & \multirow{2}{*}{$\begin{array}{l}\text { Representative } \\
\text { OTU\# }^{2}\end{array}$} & \multirow{2}{*}{$\begin{array}{l}\mathrm{NCBI} \\
\text { accession } \\
\#\end{array}$} \\
\hline & & Spring $^{y}$ & Summer & Fall & $\overline{\text { Winter }}$ & & \\
\hline \multirow[t]{21}{*}{ Cyanobacteria (CYA) } & Anabaena & & 1 & & & S67 & KT271014 \\
\hline & Aphanizomenon & & 3 & & & S272 & KT271215 \\
\hline & Arthronema & 1 & & & & S57, R51 & KP769657 \\
\hline & Chamaesiphon & 1 & & & & S405, R155 & KP769620 \\
\hline & Cyanobacteria & 3 & 15 & 12 & 4 & $\mathrm{~S} 12$ & KT270960 \\
\hline & Cylindrospermosis & & 1 & & & S269 & KT271212 \\
\hline & Leptolyngbya & 6 & & 1 & & $\mathrm{~S} 73, \mathrm{R} 50$ & KP769666 \\
\hline & Limnothrix & & 2 & & & $\mathrm{~S} 100$ & KT271044 \\
\hline & Microcoleus & 1 & & & 1 & $\mathrm{~S} 72$ & KT271019 \\
\hline & Microcystis & 1 & 10 & 3 & 1 & S1 & KT270949 \\
\hline & ML635J & & & 1 & 1 & S53 & KT271000 \\
\hline & $M L E$ & 2 & 2 & 1 & 5 & S111 & KT271055 \\
\hline & Nostoc & & 2 & & & S237 & KT271180 \\
\hline & Nostocaceae & 1 & 1 & & & S502, R162 & KP769641 \\
\hline & Phormidium & 2 & & 1 & & S83, R37 & KP769675 \\
\hline & Planktothrix & & 1 & & & S371 & KT271314 \\
\hline & Pseudanabaena & 1 & & & 1 & $\mathrm{~S} 10$ & KT270958 \\
\hline & Pseudanabaenaceae & 1 & & & & S506, R168 & KP769648 \\
\hline & Synechococcus & & 5 & & & S281 & KT271224 \\
\hline & Unclassified CYA & 5 & 9 & 6 & 6 & S88, R175 & KP769598 \\
\hline & Xenococcaceae & 1 & & & & S514, R206 & KP769652 \\
\hline$\Sigma$ & & 26 & 51 & 25 & 19 & & \\
\hline \multirow[t]{5}{*}{ Eukaryotic phytoplankton (EP) } & Chlorophyta & 11 & 2 & 3 & 17 & S2 & KT270950 \\
\hline & Cryptophyta & 2 & 4 & 1 & 7 & S3 & KT270951 \\
\hline & Stramenopila & 14 & 2 & 8 & 25 & S6 & KT270954 \\
\hline & Streptophyta & 1 & & & & S68 & KT271015 \\
\hline & Unclassified EP & 12 & & 1 & 17 & S4 & KT270952 \\
\hline$\Sigma$ & & 40 & 8 & 13 & 66 & & \\
\hline \multirow[t]{9}{*}{ Other bacteria (OB) } & Acidobacteria & & & 2 & & S325 & KT271268 \\
\hline & Candidate & 15 & 31 & 18 & 15 & S19 & KT270967 \\
\hline & Chloroflexi & 2 & & & 1 & S407, R140 & KP769621 \\
\hline & Deinococcus & 1 & 1 & & & S217 & KT271160 \\
\hline & Firmicutes & & 2 & & & S215 & KT271158 \\
\hline & Nitrospirae & & & 2 & 1 & S256 & KT271199 \\
\hline & Pelotomaculum & & 1 & & & S322 & KT271265 \\
\hline & Unclassified OB & 44 & 123 & 91 & 62 & S7 & KT270955 \\
\hline & WD272 & & & & 2 & S460 & KT271374 \\
\hline$\Sigma$ & & 62 & 158 & 113 & 81 & & \\
\hline
\end{tabular}

${ }^{\mathrm{x}}$ Taxa were determined through SINA (v1.2.11) with the least common ancestor (LCA) method based on Greengenes and Silva at ARB-Silva. Those identified to genus level are in bold text while those that are identified to family, class or order, phylum or division are in regular text ${ }^{y}$ Data has been published (Kong et al. 2017)

${ }^{z}$ OTUs grouped in previous and this study are prefixed with $\mathrm{R}$ (reservoir) and S (season), respectively 
A

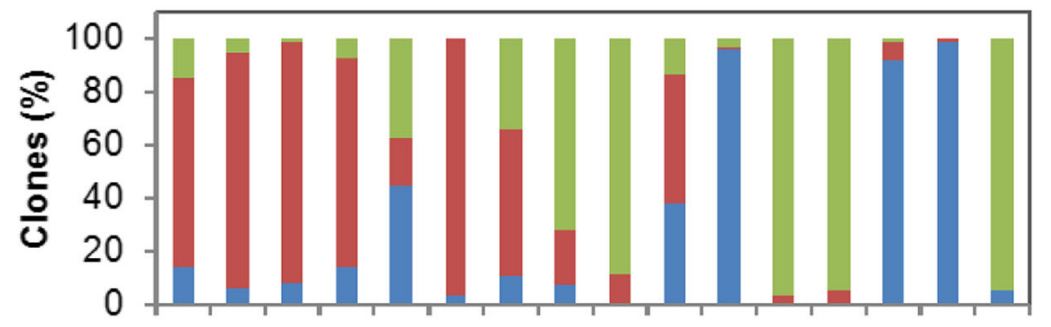

B

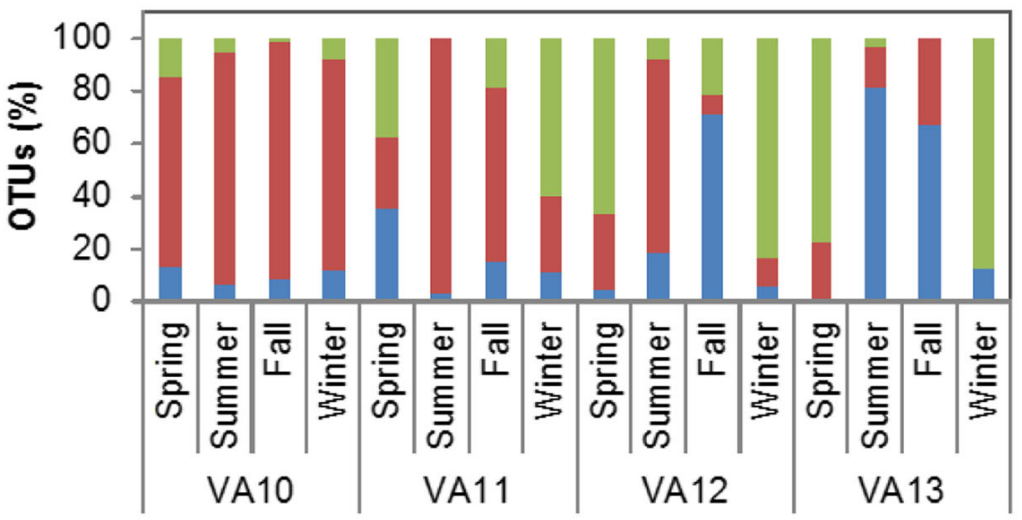

C

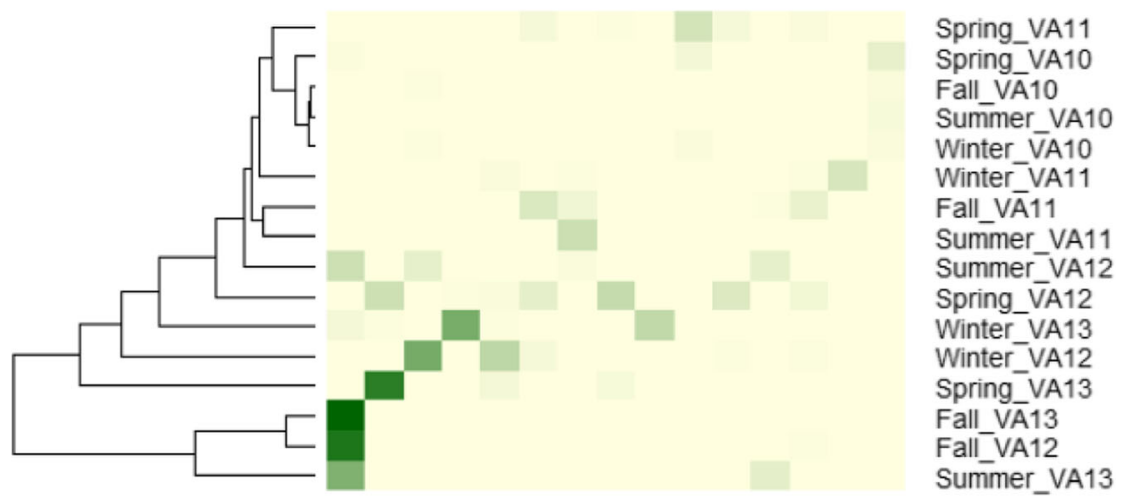

Color Key

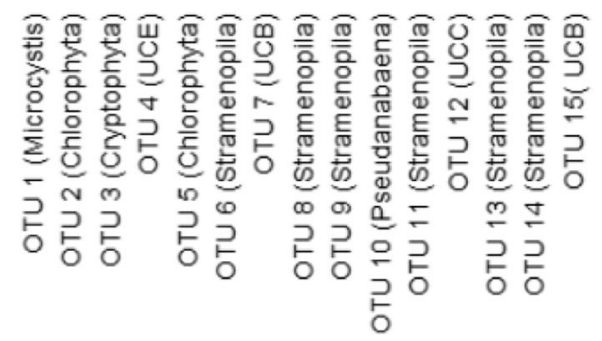

Fig. 3 Seasonal beta diversity of microbes in three reservoirs and one stream. a Community structure of three groups-cyanobacteria (CYA), eukaryotic phytoplankton (EP), and other bacteria (OB) by clone sequence. b Community structure by OTU. c Heatmap of OTUs with 10 or more clone sequences in the communities with identified taxa in parentheses. Association of samples (row) is depicted with a dendrogram 
downstream reservoir VA12. Likewise, when movement of stream water to VA11 was reduced in the fall, the dominance level of other bacteria also decreased.

\section{Correlation of seasonal microbial diversity and water quality}

The correlation between seasonal microbial diversity and water quality is presented with non-metric multidimensional scaling (NMDS) (Fig. 4). Eight taxa fit best with water quality variables although only the fitness of Microcystis, Limnothrix, Candidate, Chloroflexi, and some unclassified other bacteria was significant (Additional file 1: Table S2). Among them, cyanobacteria and other bacteria were common taxa in the summer and fall while Stramenopila phytoplankton and Chloroflexi bacteria were common spring and winter taxa (Fig. 4).

Temperature, chlorophyll $a$, and ammonium $\left(\mathrm{NH}_{4}{ }^{+}\right)$ levels were associated with microbial seasonal predominance (Fig. 4). Specifically, temperature was significantly fitted in the microbial seasonal variation. Cyanobacteria only predominated when water temperatures were over $20^{\circ} \mathrm{C}$ in VA12 and VA13 (Fig. 2, Table 1). This suggests that temperatures at $20^{\circ} \mathrm{C}$ or higher in the reservoir may trigger a bloom of cyanobacteria such as Microcystis and Limnothrix. Interestingly, chlorophyll $a$ level appeared to correlate well with predominance of Microcystis, suggesting that this parameter is a reliable measurement for monitoring Microcystis blooms. On the other hand, among the four investigated nutrients, only ammonium was associated with the presence of predominant taxa during cool seasons (Fig. 3, Additional file 1: Table S3). Chloroflexi was detected in VA10 in the spring and winter and in VA11 in the spring. However, the ammonium levels in these reservoirs varied between 0.29 and 5.18 $\mathrm{mg} / \mathrm{L}$. Similarly, Stramenopila was detected in all the reservoirs with ammonium levels that varied from winter to spring. Therefore, the correlation between these taxa and ammonium levels requires further investigation.

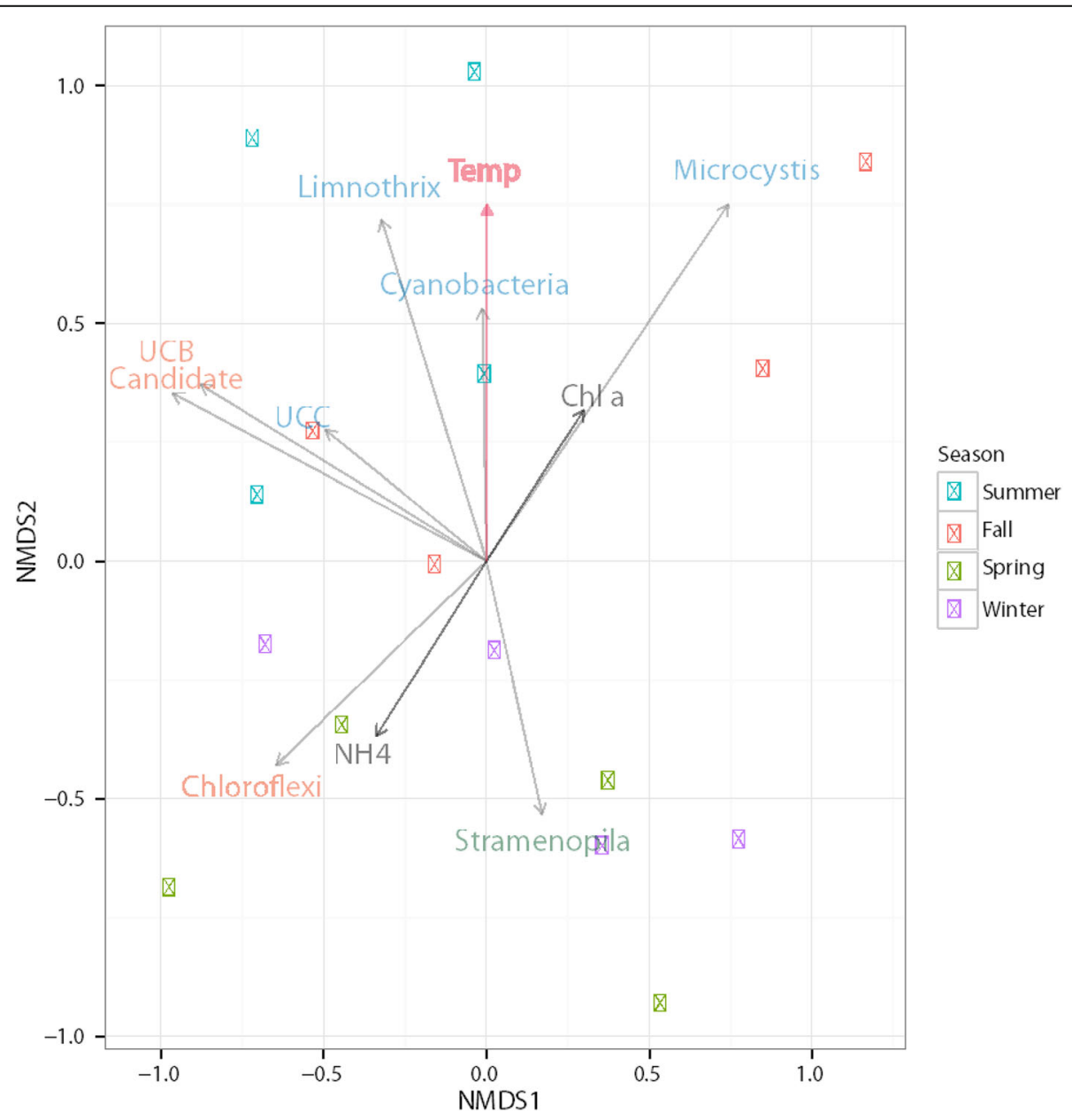

Fig. 4 Two-dimensional non-metric multidimensional scaling (NMDS) ordination plots of the best sets of water quality parameters (dark arrow lines) with maximum correlation with community dissimilarities against the best sets of taxa responsive to seasonal variation. The arrow length and direction depict the strength and nature of the relationships 


\section{Discussion}

This study revealed the seasonality of microbial community structure in multiple-reservoir agricultural runoff recycling systems with a stepwise water flow while providing additional evidence demonstrating nutrient-rich agricultural runoff's potential negative impacts on aquatic microbial diversity. These findings have several important implications.

All three reservoirs (VA11, VA12, and VA13) consistently had much lower levels of microbial diversity throughout the year when compared to that of the adjacent stream (VA10). These results are in agreement with our previous study that investigated spring microbial diversity of several water recycling systems (Kong et al. 2017). Similar negative impacts of agricultural runoff on microbial diversity were also reported in Canada (van Rossum et al. 2015). In addition to nutrients, fungicide residue in agricultural runoff also impacted microbial diversity and activities as reported in Sweden (Zubrod et al. 2015). The present study again highlights the importance of preventing agricultural runoff water from entering natural waterways and water resources.

Among the three major groups of microbes investigated in this study, cyanobacteria typically dominated the recycling irrigation reservoirs during the summer and fall while eukaryotic phytoplankton during the winter and spring as shown in VA13. These observations generally accord with the previous studies of lakes and reservoirs in Virginia (Marshall 2013), urban lake in Greece (Katsiapi et al. 2013), Bay of Quinte, Canada (Rozon and Short 2013), and high altitude lakes of India (Singh et al. 2014). Associated with the cyanobacterial dominance during the warm seasons are dramatic diurnal and seasonal fluctuations of water quality in these reservoirs (Hong et al. 2009; Zhang et al. 2015a, b; Zhang et al. 2016). The diurnal fluctuation is mostly due to photosynthesis process in which algae remove carbon dioxide from water during day time while releasing into water during night time. Likewise, the seasonal fluctuation is attributed mainly to algal bloom and subsequent decomposing process. These fluctuations of water quality have profound impacts on plant pathogens in the same reservoirs (Kong 2013; Kong and Hong 2014; Kong et al. 2009; Kong et al. 2012a, b; Zhang and Hong 2017) and crop production (Hong 2016; Hong 2017a, b; Hong et al. 2009; Zhang and Hong 2017). The cyanobacterial dominance was associated with rising temperature and nutrient level in particular of ammonium. This dominance may be affected by the introduction of exogenous microbes in an extent proportional to the quantity of water introduced from outside sourcesother bacteria carried through water from the stream in the present study. This was most obvious in the sedimentation reservoir (VA11) and to a lesser degree in the transition reservoir (VA12).
Microcystis species were identified as the most abundant cyanobacteria in these reservoirs although their implications for aquatic life, crop health, and production are yet to be elucidated. Microcystis species are known to produce harmful toxins (Feng et al. 2019; Gu et al. 2019; Lin et al. 2019; Qian et al. 2019; Ross et al. 2019; Takaara et al. 2019; Xie et al. 2019). They may also produce microcystins that could be algicidal, larvicidal, or herbicidal (Berry et al. 2008). Further investigations into their potential impacts on plant pathogens in the same reservoirs and also on crop health and productions are warranted.

It should be pointed out that the data presented here were collected from three recycling irrigation reservoirs and an associated stream at the same site. This selection of one site over four sites with a single reservoir was intended for collecting the most meaningful data. First, this recycling irrigation system had a stepwise water flow with runoff from all production areas captured in the sedimentation reservoir then overflowed to transition and retention reservoirs. As a result, the sedimentation reservoir had the most nutrient load while the retention reservoir had the least at all sampling dates except for the winter (Table 1). Second, the stream was runoff-free, so providing an ideal reference. Third, transfer of water from the stream to the sedimentation reservoir from early spring to fall months provided a window to see how exogenous microbes may change the dynamics of microbial diversity and community structure in the water recycling system. Nevertheless, the results of the present study must be interpreted with caution. Although each reservoir had a distinct seasonal pattern of microbial diversity and community structure, these seasonal patterns are yet to be validated through sampling additional sites, ideally with reservoirs of different holding capacities and water turnover times.

\section{Conclusions}

This study revealed for the first time the seasonality of microbial diversity and community structure in multiple-reservoir agricultural runoff recycling systems with a stepwise water flow. First, all three reservoirs consistently had much lower levels of microbial diversity throughout the year when compared to an adjacent runoff-free stream, highlighting the importance of preventing agricultural runoff water from entering natural waterways and water resources. Second, among the three major groups of microbes investigated in this study, cyanobacteria typically dominated the reservoirs during the summer and fall while eukaryotic phytoplankton during the winter and spring as shown in VA13. Third, the cyanobacterial dominance was associated with rising temperature and nutrient level in particular of ammonium and it was replaced by other bacteria to an extent 
proportional to the quantity of water transferred from the stream. Fourth, Microcystis species were identified as the most abundant cyanobacteria in these reservoirs although their implications for aquatic life, crop health, and production are yet to be elucidated. These findings provide a useful framework and tools for further investigations into the ecological processes in this emerging aquatic system and for better understanding, monitoring, and management of recycled water quality.

\section{Additional files}

Additional file 1: Table S1. OTU, taxon and group of individual clones in a recycled irrigation system across seasons. Table S2. Non-metric multidimensional scaling (NMDS) ordination of the best taxa responsive to seasonal variation. Table S3. Non-metric multidimensional scaling (NMDS) ordination of water quality parameters best fitting in seasonal dynamics of microbes. (DOCX $266 \mathrm{~kb}$ )

Additional file 2: Figure S1. Neighbor joining phylogenetic tree of OTUs based on 165 rDNA sequences of microbial communities in the recycled irrigation system across seasons (PDF $34 \mathrm{~kb}$ )

\section{Abbreviations}

Chla: Chlorophyll a; CYA: Cyanobacteria; DO: Dissolved oxygen; EC: Electrical conductivity; EP: Eukaryotic phytoplankton; OB: Other bacteria; OTU: Operational taxonomic units; Temp: Temperature; Turb: Turbidity

\section{Acknowledgements}

Water samples were collected and DNA extracted by G Cafá to characterize general bacterial diversity as part of the SCRI project (www.irrigationpathogens.info)

\section{Authors' contributions}

PK conceived, designed, and performed the experiments. PK and $\mathrm{CH}$ analyzed the data and wrote the paper. $\mathrm{CH}$ contributed reagents/materials/ analysis tools. PR helped in the water sample collection, measured the water quality at the time of sampling, and reviewed the manuscript. All authors read and approved the final manuscript.

\section{Funding}

This study was supported in part by the USDA National Institute of Food and Agriculture - Specialty Crop Research Initiative (SCRI, Agreement \#: 2010$51181-21140)$

\section{Availability of data and materials}

All data are included in this manuscript.

\section{Ethics approval and consent to participate}

Not applicable

\section{Consent for publication}

Not applicable

\section{Competing interests}

The authors declare that they have no competing interests.

Received: 29 November 2018 Accepted: 15 August 2019

Published online: 10 September 2019

\section{References}

Berry JP, Gantar M, Perez MH, Berry G, Noriega FG (2008) Cyanobacterial toxins as allelochemicals with potential applications as algicides, herbicides and insecticides. Marine Drugs 6:117-146

Brown LR, Ayres E (1998) The World Watch Reader on Global Environmental Issues. W. W. Norton \& Company, New York, NY, USA
Diaz RJ, Rosenberg R (2008) Spreading dead zones and consequences for marine ecosystems. Science 321:926-929

Feng B, Wang C, Wu X et al (2019) Spatiotemporal dynamics of cell abundance, colony size and intracellular toxin concentrations of pelagic and benthic Microcystis in Lake Caohai, China. J Environ Sci 84:184-196. https://doi.org/1 0.1016/.j.jes.2019.05.010

Ferber D (2001) Keeping the stygian waters at bay. Science 291:968-973

Ghimire SR, Richardson PA, Kong P et al (2011) Distribution and diversity of Phytophthora species in nursery irrigation reservoir adopting water recycling system during winter months. J Phytopathol 159:713-719

Gu Y, Gao X, Jiang Y, Peng X, Li R (2019) Molecular characterization and toxin quantification of Microcystis panniformis: a microcystin producer in Lake Taihu, China. J Environ Sci 76:359-367. https://doi.org/10.1016/j.jes.2018.05.029

Guo L (2007) Doing battle with the green monster of Taihu Lake. Science 317: 1166

Haman DZ, Smajstrala AG, Pitts DJ (2005) Efficiencies of irrigation systems used in Florida nurseries. Bul312. University of Florida - IFAS, Gainsville, FL, USA

Holdren JP (2008) Science and technology for sustainable well-being. Science 319:424-434

Hong CX (2016) Stretching the chlorine dollars - the latest research on recycled water quality. Connect (12):4-5

Hong CX (2017a) Recycled water quality dynamics and implications for ornamental crop production. Proceedings of the 41th Annual Conference of the International Plant Propagators Society - Southern Region of North America, Virginia Beach, VA, USA https://doi.org/10.17660/ActaHortic201711 7472

Hong CX (2017b) The water you mix your pesticides with could be making them less effective. Connect 4:8-9

Hong CX, Lea-Cox JD, Ross DS et al (2009) Containment basin water quality fluctuation and implications for crop health management. Irrigation Sci 29: 485-496

Hong CX, Moorman GW (2005) Plant pathogens in irrigation water: challenges and opportunities. Crit Rev Plant Sci 24:189-208

Hong CX, Moorman GW, Wohanka W, Buettner C (2014) Biology, detection and management of plant pathogens in irrigation water. American Phytopathological Society, St Paul, MN, USA

Katsiapi M, Moustaka-Gouni M, Vardaka E, Kormas KA (2013) Different phytoplankton descriptors show asymchronous changes in a shallow urban lake (L. Kastoria, Greece) after sewage diversion. Fundam Appl Limnol 182: $219-230$

Kong P (2013) Carbon dioxide as a potential water disinfestant for Phytophthora disease risk mitigation. Plant Dis 97(3):369-372. https://doi.org/10.1094/pdis09-12-0844-re

Kong P, Hong CX (2014) Oxygen stress reduces zoospore survival of Phytophthora species in a simulated aquatic system. BMC Microbiol 14:124 Open Access at http://www.biomedcentralcom/1471-2180/14/124

Kong P, Lea-Cox JD, Hong CX (2012a) Effect of electrical conductivity on survival of Phytophthora alni, P. kernoviae and P. ramorum in a simulated aquatic environment. Plant Pathol 61(6):1179-1186. https://doi.org/10.1111/j.1365-305 9.2012.02614.X

Kong P, Lea-Cox JD, Moorman GW, Hong CX (2012b) Survival of Phytophthora alni, Phytophthora kernoviae, and Phytophthora ramorum in a simulated aquatic environment at different levels of pH. FEMS Microbiol Lett 332:54-60. https://doi.org/10.1111/j.1574-6968.2012.02574.x

Kong P, Moorman GW, Lea-Cox JD, Ross DS, Richardson PA, Hong CX (2009) Zoosporic tolerance to $\mathrm{pH}$ stress and its implications for Phytophthora species in aquatic ecosystems. Appl Environ Microbiol 75:4307-4314. https:// doi.org/10.1128/aem.00119-09

Kong P, Richardson PA, Hong CX (2017) Diversity and community structure of cyanobacteria and other microbes in recycling irrigation reservoirs. PLOS ONE 12:e0173903. https://doi.org/10.1371/journal.pone.0173903

Lin YQ, Chen AW, Peng L, Luo SB, Zeng QR, Shao JH (2019) Physiological characteristics and toxin production of Microcystis aeruginosa (Cyanobacterium) in response to DOM in anaerobic digestion effluent. Sci Total Environ 685:902-910. https://doi.org/10.1016/j.scitotenv.2019.06.239

Marshall HG (2013) Phytoplankton in Virginia lakes and reservoirs. Virginia J Sci 64:1-15

Nübel U, Garcia-Pichel F, Muyzer G (1997) PCR primers to amplify 165 rRNA genes from cyanobacteria. Appl Environ Microbiol 63:3327-3332

Oksanen J, Blanchet FG, Kindt R, et al. (2015) Package 'vegan'. Community ecology package, version 2.2-1. 
Qian ZY, Chen X, Zhu HT, Shi JZ, Gong TT, Xian QM (2019) Study on the cyanobacterial toxin metabolism of Microcystis aeruginosa in nitrogen-starved conditions by a stable isotope labelling method. J Hazardous Mater 373:558564. https://doi.org/10.1016/j.jhazmat.2019.03.127

R Core Team (2013) R: a language and environment for statistical computing. R Foundation for Statistical Computing, Vienna

Ross C, Warhurst BC, Brown A, Huff C, Ochrietor JD (2019) Mesohaline conditions represent the threshold for oxidative stress, cell death and toxin release in the cyanobacterium Microcystis aeruginosa. Aquat Toxicol 206:203-211. https://doi.org/10.1016/j.aquatox.2018.11.019

Rozon RM, Short SM (2013) Complex seasonality observed amongst diverse phytoplankton viruses in the Bay of Quinte, an embayment of Lake Ontario. Freshwater Biol 58:2648-2663

Schloss PD, Gevers D, Westcott SL (2011) Reducing the effects of PCR amplification and sequencing artifacts on 165 rRNA-based studies. PLoS ONE 6(12):e27310. https://doi.org/10.1371/journal.pone.0027310

Singh Y, Khattar JIS, Singh DP, Rahi P, Gulati A (2014) Limnology and cyanobacterial diversity of high altitude lakes of Lahaulp-Spiti in Himachal Pradesh, India. J Biosci 39:643-657

Takaara T, Sasaki S, Fujii M, Ito H, Masago Y, Omura T (2019) Lectin-stimulated cellular iron uptake and toxin generation in the freshwater cyanobacterium Microcystis aeruginosa. Harmful Algae 83:25-33. https://doi.org/10.1016/j.hal.2 019.01.003

Tamura K, Stecher G, Peterson D, Filipski A, Kumar S (2013) MEGA6: molecular evolutionary genetics analysis version 6.0. Mol Biol Evol 30:2725-2729

van Rossum T, Peabody MA, Uyaguari-Diaz Ml et al (2015) Year-long metagenomic study of river microbiomes across land use and water quality. Front Microbiol 6:1405

Xie JQ, Zhao L, Liu K, Liu WP (2019) Enantiomeric environmental behavior, oxidative stress and toxin release of harmful cyanobacteria Microcystis aeruginosa in response to napropamide and acetochlor. Environ Pollut 246: 728-733. https://doi.org/10.1016/j.envpol.2018.12.056

Zhang HB, Hong CX (2017) The pH factor. Nursery Management (June):14-17.

Zhang HB, Richardson PA, Belayneh BE et al (2015a) Characterization of water quality in stratified nursery recycling irrigation reservoirs. Agric Water Manage 160:76-83

Zhang HB, Richardson PA, Belayneh BE et al (2015b) Comparative analysis of water quality between runoff entrance and middle of recycling irrigation reservoirs. Water 7:3861-3877

Zhang HB, Richardson PA, Belayneh BE et al (2016) Recycling irrigation reservoir stratification and implications for crop health and production. J Am Water Resour Assoc 52:620-631

Zubrod JP, Feckler A, Denglert D et al (2015) Inorganic fungicides as routinely applied in organic and conventional agriculture can increase palatability but reduce microbial decompositio of leaf litter. J Appl Ecol 52:310-322

\section{Publisher's Note}

Springer Nature remains neutral with regard to jurisdictional claims in published maps and institutional affiliations.

\section{Submit your manuscript to a SpringerOpen ${ }^{\circ}$ journal and benefit from:}

- Convenient online submission

- Rigorous peer review

- Open access: articles freely available online

- High visibility within the field

- Retaining the copyright to your article

Submit your next manuscript at $\boldsymbol{\nabla}$ springeropen.com 